\title{
Consumer's response to e-mail advertisement from tour and travel
} agency in Indonesia

\author{
Jonathan Kurniawan Halim, Silvia Margaretha \& Christina Rahardja Honantha \\ University of Surabaya, Surabaya, Indonesia
}

\begin{abstract}
This study aims to determine and analyze consumer response to email advertising from online tour and travel agency in Indonesia. This study used purposive sampling approach with an assessment of the researchers who can be made respondents in accordance with the characteristics of the population. The characteristics of the population were consumers who bought and used online tour and travel agency twice in the past year, lived in Indonesia, and the minimum of level education was a bachelor. The number of respondents in this study was up to 125 people. The analysis in this study used a model of SEM (Structural Equation Modeling). The result of this study indicated that with the intention of consumers to buy, build a relationship, and trust with good service then consumers will read, open, take advantage of email advertising from tour and travel agencies in Indonesia and even be willing to receive email ads in the future.
\end{abstract}

Keywords: entertainment, financial rewards, consumer's response, perceived intrusiveness

\section{INTRODUCTION}

The travel industry is currently growing. Many companies have tried to promote and sell travel services. In 2015, the online global tourism sales had reached USD 496.210.000.000. This number is predicted to grow into USD 755.940 .000 .000 by 2019 (https://www.statista.com, downloaded on March 17th, 2017). A similar situation has taken place in Indonesia, where the tourism sector may have the chance to be the source of foreign exchange for Indonesia. Therefore, the government's policy to develop tourism industry can be considered as a good strategy. "If the tourism sector grows, transportation, handicraft, and creative industries will also grow. Tourism is a sector that can be the source of foreign exchange, and eventually be the biggest in our country," said Rizal after the meeting with Minister of Tourism Arief Yahya and DKI Jakarta Governor Basuki Tjahaja Purnama.

Along with the development of the tourism sector in Indonesia, the numbers of websites offering travel services are also growing. In fact, consumers can compare information from one website to another and order from the website that meets their expectations (Rowley et al. 2001).

The result of a polling found that email advertisements sent by online tour and travel agencies in Indonesia are usually allowed by the consumers, while email spamming is rarely found. The result showed that many respondents registered their email address to the online tour and travel when they used their services, while the respondents who experienced email spamming from the online tour and travel were very few (Septianita et al. 2014).

As for the research gap that happened based on the conceptual framework of the research conducted by Schlosser et al. (1999), perceived intrusiveness mediated the entertainment variable on advertising and attitude toward email advertising (Tezinde et al. 2002). While the research of Zia ul Haq (2009) showed that the entertainment variable on advertisement had a direct effect on the attitude toward email advertising.

\section{RESEARCH METHOD}

This research was included in the basic research in the form of causal research. The type of data used was primary data by distributing online questionnaire. The measurement scale used was a numerical scale from 1 (highly disagree) to 7 (highly agree).

The population target of the research was the consumers who have experienced online tour and travel agency service twice within the past one year. As for the characteristics of the population were living in Indonesia, having a minimum of a bachelor degree, and having registered an email address to an online tour and travel agency (Morimoto et al. (2006). 
The sampling method in this research was a nonprobability sampling method. The data processing method was using SPSS 22.0 software to test the validity and the reliability. Then, SEM method was applied using Amos 21.0 software for the measurement and structural model.

According to Hair et al. 2003, Goodness of Fit was the correspondence measurement of the real covariance matrix with the expected model. On the other hand, according to Hair et al. (2010) Goodness of Fit was used to measure a model that indicated how good the model in reproducing the observed covariance matrix among the indicators. Hair et al. (2010) stated that researchers did not have to report all the model conformity index to show that a model could be considered fit. Therefore, several conformity indexes were used in the model conformity testing, such as CMIN/DF (Relative Chi-Square), CFI (Comparative Fit index), TLI (Tucker-Lewis Index), GFI (Goodness of Fit Index), and RMSEA (The Root Mean Square Error Approximation).

The next validity test was by performing the AVE (Average Variance Extracted) calculation for each variable and performing standardized loading $(\lambda)$ calculation for each indicator. The acceptable AVE score was $\geq 0.50$, and the acceptable standardized loading $(\lambda)$ score was $>0.5$ (Hair et al. (2010).

The reliability testing was performed using the Construct Reliability (CR) method for every variable. The value of the Construct Reliability (CR) which was acceptable was $\geq 0.7$ (Hair et al. 2010).

The hypothesis testing in Structural Equation Modeling (SEM) used $\alpha=5 \%$ (p). The hypothesis was accepted if the value of the Critical Ration (CR) $\geq 1.96$, otherwise, the hypothesis was not accepted or unsupported.

\section{RESULTS AND DISCUSSIONS}

The researcher conducted validity testing on the early stage using 30 questionnaires resulting in Pearson correlation in each statement scoring a total of a lower significance score of $0.05(\alpha=5 \%)$, which meant that all items in the statements were valid.

The reliability testing was used to find out the consistency of the measuring instrument. If the Cronbach Alpha score was bigger than 0.6, the statement items could be considered reliable. The reliability testing was performed on 30 respondents. The data analysis showed that the Cronbach Alpha value of the quality of information, entertainment, financial rewards, perceived intrusiveness, attitudes toward e-mail advertising, intention toward the sender, and consumer response variables was higher than 0.6. Therefore, the entire variables in this research were considered reliable.

The measurement model should fulfill the criteria of the Goodness of Fit value so that the further analysis was allowed to be conducted. CMIN/DF was a calculation of the chi-square $\left(\mathrm{x}^{2}\right)$ value divided by the degree of freedom (DF). The value of CMIN/DF which showed a good fit was $<3$. Table 1 shows that the value of CMIN/DF was considered a good fit with the value of 1.269 and fulfilled the criteria of Goodness of Fit.

RMSEA was the index used to address the tendency of Chi-Square $\left(\lambda^{2}\right)$. The value of RMSEA is considered good fit if it is below or equal to 0.08, while it can be considered as close fit if the RMSEA $<0.05$. The result showed that the value of RMSEA was considered good fit with a score of 0.033 and fulfilled the criteria of goodness of fit.

The GFI can be considered as a good model (good fit) if the value of GFI $\geq 0.9$. However, if the value of GFI is $0.8 \leq \mathrm{GFI} \leq 0.9$, it can be considered as marginal fit. The result of the research showed that the GFI could be considered as marginal fit with the score of 0.820 , but it still fulfilled the criteria of goodness of fit.

The CFI can be considered as a good model (good fit) if the value of CFI $\geq 0.9$. Meanwhile, if the value of CFI is $0.8 \leq \mathrm{CFI} \leq 0.9$, it can be considered as marginal fit. The result of the research showed that the value of the CFI could be considered as a good fit with the value of 0.961 which was higher than 0.90 and fulfilled the criteria of goodness of fit.

The TLI can be considered as a good model (good fit) if the value of TLI $\geq 0.9$. Meanwhile, if the value of TLI is $0.8 \leq \mathrm{TLI} \leq 0.9$, it can be considered as marginal fit. (Hair et al. 2010). The result of the research showed that the value of the TLI could be considered as good fit with the value of 0.955 which was higher than 0.90 and fulfilled the criteria of goodness of fit.

Table 1. The Result of the Structural Model Goodness of Fit Test

\begin{tabular}{lllll}
\hline No. & Fit Test & Fit Criteria & Result & Note \\
\hline 1. & CMIN/DF & CMIN/DF $<3$ & 1.466 & Good Fit \\
2. & RMSEA & RMSEA $\leq 0.08$ & 0.043 & Good Fit \\
3. & GFI & GFI $\geq 0.90$ & 0.792 & Not Fit \\
4. & CFI & CFI $\geq 0.90$ & 0.930 & Good Fit \\
5. & TLI & TLI $\geq 0.90$ & 0.923 & Good Fit \\
\hline
\end{tabular}

The validity testing on the measurement model can be seen from the value of AVE (Average Variance Extracted) which demonstartes the value of the average variance extracted (AVE) is below 0,5. However, according to Fornell \& Larcker (1981) in Huang, Wang, Wu and Wang (2013), the value of AVE which is below 0.5 is acceptable as long as the 
score of the construct reliability is above 0.6. The score of the whole construct showed a construct reliability value of $\geq 0.7$ which means that the whole construct could be considered reliable.

Thus, the research may proceed to the next stage. The following table shows the value of the Goodness of Fit. Table 1 show that the values of the structural model Goodness of Fit have fulfilled the criteria of Goodness of Fit. Therefore, the analysis may proceed to hypothesis testing.

The hypothesis testing was conducted by addressing the value of CR and the value of $\rho$. The value of $\mathrm{CR} \geq 1.96$ and the value of $\rho<0.05$, so the hypothesis could be considered significant. The estimated value showed the significance of the effect among variables on every path. The bigger the estimated value, the bigger the effect among variables, and it also goes both ways.

Table 2. The Result of Hypothesis Testing

\begin{tabular}{|c|c|c|c|c|c|c|}
\hline \multirow{2}{*}{\multicolumn{2}{|c|}{$\begin{array}{l}\text { Hypothesis } \\
\text { Permission }\end{array}$}} & \multirow{2}{*}{$\begin{array}{l}\text { Std } \\
\text { Est }\end{array}$} & \multirow{2}{*}{ S.E. } & \multirow{2}{*}{ C.R. } & \multirow{2}{*}{$\mathrm{P}$} & \multirow{2}{*}{ Note } \\
\hline & & & & & & \\
\hline H1a & $\begin{array}{l}\text { QUAL } \\
\rightarrow \quad \text { IN- } \\
\text { TRV }\end{array}$ & -0.015 & 0.066 & -0.179 & 0.858 & $\begin{array}{l}\text { Not } \\
\text { supported }\end{array}$ \\
\hline $\mathrm{H} 2 \mathrm{a}$ & $\begin{array}{l}\text { ENT } \rightarrow \\
\text { INTRV }\end{array}$ & -0.099 & 0.063 & -1.183 & 0.220 & $\begin{array}{l}\text { Not } \\
\text { supported }\end{array}$ \\
\hline $\mathrm{H} 3 \mathrm{a}$ & $\begin{array}{l}\text { FIN } \rightarrow \\
\text { INTRV }\end{array}$ & -0.691 & 0.146 & -5.826 & $* * *$ & Supported \\
\hline $\mathrm{H} 4 \mathrm{a}$ & $\begin{array}{l}\text { INTRV } \\
\rightarrow \text { ATT } \\
\text { Ads }\end{array}$ & -0.294 & 0.142 & -2.977 & $* * *$ & Supported \\
\hline $\mathrm{H} 5 \mathrm{a}$ & $\begin{array}{l}\text { Value } \\
\rightarrow \quad \text { IN- } \\
\text { TRV } \rightarrow \\
\text { ATT }\end{array}$ & & & & & $\begin{array}{l}\text { Not } \\
\text { supported }\end{array}$ \\
\hline H6a & $\begin{array}{l}\text { ATT } \rightarrow \\
\text { INT }\end{array}$ & 0.235 & 0.085 & 2.438 & 0.015 & Supported \\
\hline $\mathrm{H} 7 \mathrm{a}$ & $\begin{array}{l}\mathrm{ATT} \rightarrow \\
\mathrm{C}_{-} \mathrm{RES} \\
\mathrm{P}\end{array}$ & 0.048 & 0.073 & 0.588 & 0.560 & $\begin{array}{l}\text { Not } \\
\text { supported }\end{array}$ \\
\hline H8a & $\begin{array}{l}\mathrm{INT} \rightarrow \\
\mathrm{C}_{-} \mathrm{RES} \\
\mathrm{P}\end{array}$ & 0.642 & 0.094 & 6.841 & $* * *$ & Supported \\
\hline $\mathrm{H} 10 \mathrm{a}$ & $\begin{array}{l}\text { ENT } \rightarrow \\
\text { ATT }\end{array}$ & 0.094 & 0.108 & 0.950 & 0.342 & $\begin{array}{l}\text { Not } \\
\text { Supported }\end{array}$ \\
\hline
\end{tabular}

Table 2 shows that hypothesis 1 a had an insignificant effect on the Critical Ration value of -0.179 and the $\rho$ value of 0.858 which means that the hypothesis was not supported. Hypothesis 2 a did not have a significant effect on the Critical Ratio value of -1.183 and the $\rho$ value of 0.220 which means that the hypothesis was not supported. Hypothesis $3 \mathrm{a}$ had a significant value with the Critical Ratio value of 5.826 and the $\rho$ value of $<0.05$ which means that the hypothesis was accepted. Hypothesis $4 \mathrm{a}$ had a significant value with the Critical Ratio value of -2.977 and the $\rho$ value of $<0.05$ which means that the hy- pothesis was accepted. Hypothesis 5 did not have a mediation effect because the quality of information and entertainment variable had an insignificant relation which means that the hypothesis was not supported. Hypothesis 6a had a significant value with the Critical Ratio value of 2.438 and the $\rho$ value of 0.015 which means that the hypothesis was accepted. Hypothesis 7a did not have a significant effect on the Critical Ratio value of 0.588 and the $\rho$ value of 0.560 which means that the hypothesis was not supported. Hypothesis $6 \mathrm{a}$ had a significant value with the Critical Ratio value of 6.841 and the $\rho$ value of $<0.05$ which means that the hypothesis was accepted. Hypothesis 10a did not have a significant effect with the Critical Ratio value of 0.950 and the $\rho$ value of 0.342 which means that the hypothesis was not supported. From table 2, it can be concluded that of the nine hypotheses there were five hypotheses which were not supported namely hypothesis $1 \mathrm{a}, 2 \mathrm{a}$, 5a, 7a, and 10a.

\section{CONCLUSIONS}

Based on the result of the research, it can be concluded that of the nine hypotheses, four of them were supported and five of the hypotheses were not supported, such as the quality of information did not have a significant negative effect on the perceived intrusiveness for permission based email in Indonesia (hypothesis 1a), entertainment did not have a significant negative effect on perceived intrusiveness for permission based email in Indonesia (hypothesis 2a), perceived intrusiveness did not mediate advertising value and attitudes toward e-mail advertising for permission based email in Indonesia (hypothesis 5), attitudes toward e-mail advertising did not have significant positive effect on the consumer response for permission based email in Indonesia (hypothesis 7a), entertainment did not have significant positive effect on the attitudes toward e-mail advertising for permission based email in Indonesia (hypothesis 10a). However, the existing model has described the result of the data in the field. It is shown by the result of the testing the goodness of fit which shows that the level of model fitness on the data can be considered good.

Based on the result of the research, the intention toward the sender on consumer response had the biggest effect compared to the rest. Therefore, the management of online tour and travel agency focused more on making the customers intent to purchase and build a good relationship with the online tour and travel agency. It will build a positive perspective and trust on the services offered by the online tour and travel agency. It will also cause the 
consumers read and accept the e-mail offers from the tour and travel agency more often in the future (Milne et al. 1993).

\section{REFERENCES}

Milne, G. \& Gordon, M.E. 1993. Direct mail privacyefficiency trade-offs within an implied social contact framework, Journal of Public and Marketing 12(2): 206216.

Morimoto, M. \& Chang, S. 2006. Consumers' attitudes toward unsolicited commercial e-mail and postal direct mail marketing methods: intrusiveness, perceived loss of control, and irritation, Journal of Interactive Advertising 7(1): 8-20.

Rowley, J. 2001. Remodeling marketing communications in an Internet environment, Internet Research 11(3): 203-212.

Septianita, W., Agus, W.W., \& Arif, A. 2014. Effect System Quality, Information Quality, Service Quality of Rail Ticketing System (RTS) to User Satisfaction 1(1): 53-56.

Schlosser, A.E., Shavitt, S., \& Kanfer, A. 1999. A Survey of internet users' attitudes toward internet advertising, Journal of Interactive Marketing 13(3): 34-54.

Tezinde, T., Smith, B., \& Murphy, J. 2002. Getting permission: exploring factors affecting permission marketing, Journal of Interactive Marketing 16(4): 28-36.

Zia ul Haq. 2009. E-mail advertising: A study of consumer attitude toward e-mail advertising among Indian users, 8 207223. 